\title{
Teoria Crítica, Democracia e Esfera Pública: Concepções e Usos na América Latina*
}

\author{
Leonardo Avritzer \\ Sérgio Costa
}

\begin{abstract}
s chamadas teorias da transição democrática constituíram, como se sabe, um dos filões mais ricos das ciências sociais no Brasil e na América Latina nas últimas décadas. Realizando uma ampla radiografia institucional dos países que se democratizavam, trabalhos como aquele editado por O'Donnell et alii (1986) constituíram, pelo menos até os anos 90, a forma por excelência de estudar e interpretar o autoritarismo e o momento em que a incerteza sobre os resultados do jogo político e a força reguladora de regras universais se impuseram novamente sobre o poder de um ator único - tal a definição de democratização das teorias da transição. Mais ainda, as teorias da transição consagraram a recém surgida ciência política, que na maioria dos países latino-americanos somente a partir dos anos 70 se afirma como um campo de investigação independente, com uma metodologia própria e paradigmas de análises distintos.
\end{abstract}

Ao longo dos anos 90, vai se consolidando, contudo, uma nova abordagem sociológica da democratização, a qual, refuta a homologia en-

\footnotetext{
* Este artigo retoma partes de trabalhos anteriores dos autores e mais notadamente artigos escritos para um dossiê sobre espaço público publicado pela revista Metapolítica (Avritzer, 1999; Costa, 1999) e dois livros recentes (Avritzer, 2002; Costa, 2002). Trabalho apresentado no XXVIII Encontro Anual da Associação Nacional de Pós-Graduação e Pesquisa em Ciências Sociais - ANPOcs, Caxambu, MG, 26-30 de outubro de 2004.

DADOS - Revista de Ciências Sociais, Rio de Janeiro, Vol. 47, nำ 2004, pp. 703 a 728.
} 
tre os processos de construção institucional e de democratização societária subentendida nas teorias da transição. O que se procura mostrar é que, ao lado da construção de instituições democráticas (eleições livres, parlamento ativo, liberdade de imprensa etc.), a vigência da democracia implica a incorporação de valores democráticos nas "práticas cotidianas" (Avritzer, 1996:143). Nesse caso, a análise dos processos sociais de transformação verificados no bojo da democratização não poderia permanecer confinada na esfera institucional, deveria, ao contrário, penetrar o tecido das relações sociais e da cultura política gestadas nesse nível, revelando as modificações aí observadas. Dessa maneira, a crítica sociológica às teorias da transição indica a necessidade de estudar, de forma reconstrutiva, o modelo concreto de relacionamento entre o Estado, as instituições políticas e a sociedade, mostrando que nessas interseções habita, precisamente, o movimento de construção da democracia. A democratização, nesse caso, já não é mais o momento de transição, é o processo permanente e nunca inteiramente acabado de concretização da soberania popular (ver Costa, 1994; Olvera, 1999).

Para a construção de tal abordagem sociológica da democratização, a incorporação de conceitos como sociedade civil e espaço público, desenvolvidos mais adequadamente em outros contextos, desempenha uma função-chave. Eles permitem a ressignificação da imensa gama de trabalhos particulares que, em uma operação quase etnográfica, haviam estudado os diferentes atores surgidos ao longo da democratização e suas formas de relacionamento com o Estado e as instituições, permitindo que fossem contextualizados em um marco teórico amplo. Essas categorias, não obstante, não são de uso exclusivo daquele campo que aqui se denomina de tratamento sociológico da democratização. Elas apresentam, na verdade, uso múltiplo e diverso, assumindo em cada contribuição uma conotação própria. Dessa maneira, a adaptação de tais conceitos ao contexto latino-americano implica a explicitação do sentido preciso que eles assumem. No que diz respeito à idéia de sociedade civil, pode-se dizer que se processou nos últimos anos, em consonância com o debate mundial sobre o tema, a construção de uma teoria da sociedade civil latino-americana e de seus usos analíticos no contexto de uma interpretação sociológica da democratização e das novas democracias (ver, entre outros, Avritzer, 1996; Costa, 1997; Olvera, 1999, além do estudo inter-regional sobre 
sociedade civil e governance publicado em Dagnino, 2002a; Panfichi, 2002; Olvera, 2003).

Já a discussão das possibilidades de uso do conceito espaço público no contexto dos estudos sobre a democratização latino-americana é mais recente e ainda muito incipiente. O presente artigo pretende contribuir para este debate. Em primeiro lugar, reconstruímos sumariamente a trajetória do conceito espaço público na teoria crítica, mostrando como as definições e usos do conceito vão se modificando ao longo do tempo, até chegar à forma, assumida nos anos 90, de um modelo discursivo de espaço público. Em seguida, apresentamos algumas críticas recentes a tal modelo, a nosso ver relevantes para o estudo do contexto latino-americano, além de uma breve digressão sobre o conceito espaço público mundial ou global, ao qual, malgrado vir merecendo um uso cada vez mais freqüente - também na América Latina -, faltam consistência e plausibilidade teóricas. Por fim, buscamos passar em revista crítica alguns usos do conceito de espaço público na América Latina, concluindo que adaptações e correções ao modelo discursivo podem fazer de tal concepção uma ferramenta útil para o estudo de transformações recentes na América Latina.

\section{TEORIA CRÍTICA E ESPAÇO PÚBLICO}

\section{Da Sociedade de Massas à Mudança Estrutural da Esfera Pública ${ }^{1}$}

O conceito de esfera pública representou um elemento central no processo de reconstrução da teoria crítica na segunda metade do século XX (Habermas, 1990; Calhoun, 1992; Thompson, 1995; Melucci, 1996). Significou a continuação de uma tradição crítica sobre a cultura de massas iniciada pela Escola de Frankfurt (Jay, 1973) e, ao mesmo tempo, produziu uma grande mudança dentro desta tradição, através da recuperação de um fundamento normativo que permitiu estabelecer uma nova relação entre a teoria crítica e a teoria democrática.

Duas diferentes dimensões do conceito de esfera pública possibilitaram que a categoria cumprisse a função de divisor de águas entre a análise da indústria cultural de Adorno e Horkheimer e as contribuições à teoria democrática contemporânea (Dryzek, 1990; Benhabib, 1995; Gutman, 1994; Habermas, 1992b). Em primeiro lugar, através desse conceito se identificou, no advento da modernidade, uma esfera para a interação legal de grupos, associações e movimentos, o qual 
abriu um novo caminho dentro da teoria democrática, mais além do debate entre os elitistas (Schumpeter, 1944; Downs, 1956; Sartori, 1987) e os democratas participativos (Pateman, 1970; Held, 1987). Introduziu-se, assim, a possibilidade de uma "relação argumentativa crítica" com a organização política, no lugar da participação direta. Dessa forma, abriu-se espaço para uma nova forma de relação entre racionalidade e participação.

A segunda dimensão do conceito de esfera pública referida acima diz respeito à tensão entre autonomia da crítica cultural e o caráter comercial do processo de produção cultural (Habermas, 1990; Thompson, 1990). Tal tensão diz respeito à infiltração mútua das esferas pública e privada (Habermas, 1990) e representa a continuação da análise de Adorno e Horkheimer (1964) sobre a perda de autonomia do campo cultural.

O conceito de esfera pública de Habermas levou ao desenvolvimento de duas áreas de investigação na teoria social muito produtivas e, não obstante, contraditórias: a primeira inclui as teorias sobre movimentos sociais e sociedade civil (Melucci, 1985; 1989; 1996; Keane, 1988; Cohen, 1985; Goldfarb, 1989). Ambas as teorias, a despeito de suas diferenças, se inspiram na idéia do desenvolvimento de uma esfera dialógica e interativa a que pertencem os movimentos sociais e as associações voluntárias. Nesse âmbito se dá a tematização de novas questões e o estabelecimento de fluxos de comunicação característicos de uma forma de ação que suspende, temporariamente, os fins imediatos de uma interação específica, interpelando a validade moral dos assuntos em questão (Habermas, 1981; 1992a). No âmbito da teoria crítica, os processos de legitimação democráticos relacionam-se com tal forma de ação comunicativa.

A segunda área de desenvolvimento dentro da teoria crítica impulsionada pela análise de Habermas no livro Mudança Estrutural da Esfera Pública é o estudo dos meios de comunicação de massa (Deetz, 1992; Thompson, 1990; 1995). Diferentemente do primeiro caso, o desenvolvimento da pesquisa sobre os meios de comunicação de massa, baseando-se na suposição de que há uma semelhança entre o consumo de bens materiais e culturais, mostrou-se, em um primeiro momento, pouco produtivo. Tanto é assim que o próprio Habermas se veria forçado nos anos 90, conforme mostramos abaixo, a revisar suas consi- 
derações sobre as formas de recepção dos meios de comunicação de massa.

No livro Mudança Estrutural da Esfera Pública, Habermas parte da análise do desenvolvimento do capitalismo mercantil na Europa do século XVII, para mostrar que este desenvolvimento provocou a emergência de um espaço entre a esfera privada e o Estado, espaço este caracterizado pela discussão livre e racional do exercício da autoridade política. Conforme o autor, há duas mudanças fundamentais subjacentes à emergência dessa esfera. A primeira refere-se ao que ele denomina de separação entre os interesses vinculados à economia doméstica e a subjetividade. Assim, a emergência do espaço público encontra-se vinculada ao desacoplamento da capacidade reflexiva do indivíduo da esfera dos interesses materiais. Os públicos culturais estão, por isso, vinculados não apenas à circulação comercial de idéias, mas também ao fato de que a família e a subjetividade, ao se desvincularem das atividades "não reflexivas", permitem aos indivíduos estabelecer relações "puramente humanas" uns com os outros (Arendt, 1959).

A segunda transformação na antiga Europa burguesa sublinhada por Habermas refere-se à mudança na relação da burguesia com o poder. A burguesia é a primeira classe governante cuja fonte de poder é independente do controle do Estado e que se localiza no nível privado. Sua relação com o poder é, nesse sentido, estruturalmente diferente de outras classes na história, uma vez que renuncia ao exercício direto do governo, reivindicando, contudo, o direito de ter conhecimento do que faz o Estado. Tal demanda serviu, assim, para conferir um caráter público às relações entre Estado e sociedade. Isto é, como resultado da reivindicação por parte da burguesia da prestação pública de contas, emergiu uma esfera constituída por indivíduos que buscam submeter decisões da autoridade estatal à crítica racional.

A descrição de Habermas da emergência de uma esfera pública na modernidade não constitui uma ruptura com a Escola de Frankfurt, como poderia parecer à primeira vista. Seu argumento está relacionado com a idéia da decadência do moderno em virtude da maneira como se tematiza a separação entre o público e o privado. Com o desenvolvimento da modernidade, tal separação é substituída por uma influência progressiva da sociedade sobre o Estado e por uma estatização crescente da sociedade (Habermas, 1990). A tentativa de Haber- 
mas de localizar as características de um público cultural e político no primeiro período burguês, assim como sua ênfase nas atividades não comerciais dos públicos culturais, rompe com a possibilidade de conectar o avanço da modernidade com uma tensão crescente entre o mercado e a esfera pública. Com efeito, os desenvolvimentos mais significativos da teoria crítica apontaram nessa direção, destacando, principalmente, a emergência de públicos que interpelam criticamente os meios de comunicação nas sociedades contemporâneas.

\section{A Construção do Modelo Discursivo de Esfera Pública}

Desde o importante prefácio à reedição alemã de 1990, Habermas explicita a revisão das teses centrais do Mudança Estrutural da Esfera Pública, mostrando que o espaço público continua estabelecendo, como órbita insubstituível de constituição democrática da opinião e da vontade coletivas, a mediação necessária entre a sociedade civil, de um lado, e o Estado e o sistema político, de outro.

A revisão analítica realizada naquele prefácio pode, para nossos propósitos presentes, ser desdobrada em três momentos distintos:

1) A partir das novas pesquisas da sociologia da comunicação e do comportamento político, o autor relativiza a tese linear anterior de que os cidadãos, na sociedade de massas, teriam se transformado, de politicamente ativos em privatistas, de atores da cultura em consumidores de entretenimento. Não se deve subestimar, segundo o autor, o potencial de crítica e de seleção de um público capaz de preservar suas diferenciações internas e sua pluralidade, a despeito da pressão cultural e politicamente homogeneizadora da mídia.

2) Partindo do modelo em dois níveis de sociedade (a diferenciação entre sistema e mundo da vida) desenvolvido em sua Teoria da Ação Comunicativa, Habermas mostra que a força sociointegrativa que emana das interações comunicativas voltadas para o entendimento, próprias do mundo da vida, não migra imediatamente para o plano político, pacificando aí as diferenças de interesses e disputas de poder existentes. Recusa-se a fórmula rousseauniana, segundo a qual a virtude cívica dos cidadãos individuais proporcionará per se a constituição de um conjunto de cidadãos orientados para o bem comum. A fonte da legitimidade política não pode ser, conforme Habermas, a vontade dos cidadãos individuais, mas o resultado do processo co- 
municativo de formação da opinião e da vontade coletiva. É esse o processo que, operado dentro da esfera pública, estabelece a mediação entre o mundo da vida e o sistema político, permitindo que os impulsos provindos do mundo da vida cheguem até as instâncias de tomada de decisão instituídas pela ordem democrática (Habermas, 1990:37 e ss.).

3) Segue-se a percepção de uma ambivalência constitutiva da esfera pública: nela desembocam tanto os fluxos comunicativos originados no mundo da vida - portanto gestados em relações voltadas para o entendimento - quanto os esforços de utilização dos meios de comunicação para a produção de lealdade política e para influenciar as preferências de consumo. A canalização dos fluxos comunicativos provindos do mundo da vida para a esfera pública é operada, fundamentalmente, pelo conjunto de associações voluntárias desvinculadas do mercado e do Estado a que se denomina sociedade civil. As chances de tais associações influenciarem efetivamente a esfera pública, se contrapondo aos atores sistêmicos, marcando-a com seus temas, permanecem grandeza a ser, em cada caso, avaliada empiricamente (idem:45 e ss.).

Em trabalhos subseqüentes, Habermas (1992a; 1992b) desenvolve e amplia a concepção aqui brevemente delineada, procurando detalhar o papel de uma esfera pública "politicamente influente" dentro de sua concepção teórico-discursiva da democracia. Nesses trabalhos, o autor detalha a forma como, nos contextos democráticos, os procedimentos legais e políticos institucionalizados asseguram que os processos espontâneos de formação de opinião sejam considerados nas instâncias decisórias. Assim, a força sociointegrativa da solidariedade, assente nos impulsos comunicativos do mundo da vida, contrabalançaria os outros dois recursos que suprem a "carência de integração e coordenação" das sociedades modernas, a saber, o dinheiro e o poder (Habermas, 1992b:23).

Cabe aos atores da sociedade civil nesse modelo discursivo de democracia um papel duplo: de um lado, eles são responsáveis pela preservação e ampliação da infra-estrutura comunicativa próprias do mundo da vida e pela produção de microesferas públicas associadas à vida cotidiana. Ao mesmo tempo, tais atores canalizam os problemas tematizados na vida cotidiana para a esfera pública, tratando de 
“[...] apresentar novas contribuições para a solução de problemas, de oferecer novas informações e de corroborar os bons motivos, denunciando os maus, de forma a introduzir um impulso nos ânimos capaz de alterar os parâmetros constitucionais da formação da vontade política e de pressionar os parlamentos, os judiciários e os governos em favor de determinadas políticas" (Habermas, 1992a:448).

Ao mesmo tempo, Habermas insiste na necessidade de autolimitação da influência dos atores da sociedade civil, sob dois aspectos fundamentais. O primeiro diz respeito à complexidade, qual seja, para que possam funcionar como catalisadoras dos processos espontâneos de formação da opinião, as organizações da sociedade civil não podem transformar-se em estruturas formalizadas, dominadas pelos rituais burocráticos. De outra forma, o ganho de complexidade poderia significar a rendição aos imperativos organizacionais e o conseqüente distanciamento da base (Habermas, 1985:423). A segunda autolimitação diz respeito diretamente à questão do poder. Para Habermas, os atores da sociedade civil não podem exercer poder administrativo, isto é, a influência destes sobre a política se faz através das mensagens que, percorrendo os mecanismos institucionalizados do Estado constitucional, alcançam os núcleos decisórios. Dessa forma, procura-se afastar a idéia de que a sociedade civil possa assumir funções que cabem ao Estado.

\section{Correções e Complementações ao Modelo Discursivo: New Publics, Counter Publics, Diasporic Publics, Deliberative Publics}

Ainda que constitua, com larga margem, o modelo teórico de espaço público mais detalhado e acurado presente no debate contemporâneo, a concepção discursiva de esfera pública, conforme desenvolvida por Habermas ao longo dos anos 90, mereceu críticas e complementações importantes, as quais nos parecem relevantes considerar quando se pretende usar tal modelo fora de seu berço de origem na Europa.

A primeira complementação vem de Cohen e Arato (1992), autores que desenvolvem sua teoria da sociedade civil no contexto de um intenso diálogo com o autor da teoria da ação comunicativa. Cabe destacar aqui a ênfase conferida por Cohen e Arato ao desenvolvimento histórico dos chamados new publics. Conforme mostram os autores, ao lado do crescimento incontrolado da grande mídia e da penetração 
da cultura pelas lógicas do dinheiro e do poder que dele decorre, verifica-se um processo coetâneo de desprovincialização e modernização do mundo da vida, que culmina com a criação e expansão de novos públicos e novos loci de realização de formas críticas de comunicação - contextos de difusão de subculturas, movimentos sociais, microespaços alternativos etc. Trata-se aqui de meios culturais marcados pela produção e circulação de idéias e formas de vida pós-tradicionais, as quais colocam em movimento dinâmicas de inovação cultural e contestação dos padrões sociais estabelecidos no plano, por exemplo, das representações de gênero, das relações étnicas etc.

As forças de renovação e transformação mobilizadas pelos novos públicos não se restringem à esfera da cultura ou do comportamento, uma vez que eles pressionam por mudanças no padrão da comunicação pública e podem gerar transformações duradouras mesmo na política institucionalizada:

“[...] enquanto o núcleo da esfera pública política, constituída por parlamentos e a grande mídia, mantém-se, antes (mas não da mesma forma em todas as partes!) fechada e inacessível, uma pluralidade de públicos alternativos, diferenciada mas inter-relacionada, revivifica de tempos em tempos os processos e a qualidade da comunicação pública. Com a emergência de novos tipos de organização política, até mesmo a discussão pública nos parlamentos e nas convenções partidárias tende a ser afetada [...]" (idem:460).

O argumento de Cohen e Arato ganha contundência na crítica de Fraser ao modelo habermasiano e no apelo pelo reconhecimento da importância dos chamados subaltern counterpublics (Fraser, 1992; 2002). Para a autora, a idéia de uma esfera pública nacional única e abrangente não considera as relações assimétricas de poder que marcam, historicamente, os processos de constituição das esferas públicas contemporâneas. Ou seja, em sua própria formação, a esfera pública apresenta mecanismos de seleção que implicam a definição prévia de quem serão os atores que serão efetivamente ouvidos e quais serão os temas que efetivamente serão tratados como públicos. Nesse contexto, minorias étnicas, grupos discriminados e mulheres são excluídos $a$ priori da esfera pública ou merecem nela um lugar subordinado.

Os contrapúblicos subalternos, ao denunciarem os "vícios de origem" dos espaços públicos nacionais, constituem, por isso, forças não 
de desestabilização, mas de democratização e ampliação da política nacional.

Gilroy (1993) acrescenta um elemento importante à crítica de Fraser, ao estudar uma forma de manifestação daquilo que gostaríamos de chamar de diasporic publics. Refere-se aqui ao chamado espaço cultural do Atlântico Negro, entendido como um contexto de ação transnacional, formado no âmbito da diáspora africana iniciada com a escravidão moderna e a imigração forçada da África para as Américas. A alusão ao Atlântico Negro implica mais que reivindicar a igualdade de direitos e possibilidades de participação na política contemporânea e no âmbito da esfera pública burguesa. Trata-se, em consonância e complementarmente àquilo que fizeram as filósofas feministas, de colocar em discussão o próprio processo de construção da política moderna enquanto espaço privilegiado de representação dos interesses e das visões de mundo do homem branco. Assim, na medida em que a política contemporânea se rege pelo império da palavra, pela imposição da separação entre ética e estética, performance e racionalidade, decide-se previamente o jogo político em contra àqueles que, por força de sua inserção na história moderna, não puderam assumir o controle dos mecanismos de produção e reprodução dos discursos de poder considerados legítimos em cada Estado-nação particular.

A história da diáspora africana, ao contrário, desenvolve-se fora da órbita da política formal, valendo-se, fundamentalmente, da performance, da dança e da música como forma de sua constituição. Por outro lado, desde a sua origem, a diáspora africana não pôde ser reduzida e retraduzida na dinâmica nacional da política contemporânea. Ao contrário, sempre se verificou uma tensão entre a busca de homogeneidade étnica no contexto de nações modernas e a presença de escravos negros e, depois, de seus descendentes, tratados como inferiores e ameaças aos projetos nacionais. Decorre dessa posição particular aquilo que Paul Gilroy, referindo-se a Du Bois, chama de dupla consciência dos negros no âmbito da modernidade. Trata-se de uma inserção ambivalente na história, caracterizada, por um lado, pela inclusão efetiva no processo de construção da modernidade e, por outro, pela exclusão sistemática da vida política no âmbito dos Estados-nação.

A sugestão de Gilroy é que se tome a contracultura do Atlântico Negro não simplesmente como mais um repertório de manifestações ar- 
tísticas e culturais, dissociadas da política, mas como um discurso filosófico que reinterpreta a modernidade e reconta sua história, a partir da perspectiva de quem sempre esteve fora das narrativas nacionais com seus heróis brancos.

As críticas de Fraser e Gilroy representam para o modelo discursivo, e seu elogio implícito das possibilidades do diálogo e do universalismo, uma correção importante: tais críticas implicam a necessidade de construir estruturas específicas de captação dos interesses e públicos subalternos, além de alertarem para o risco implícito da ênfase do modelo discursivo na comunicação verbal. Com efeito, se o espaço público não se mostrar poroso à força expressiva não apenas dos argumentos, mas também da performance e das formas não-verbais de comunicação, este pode se prestar, indefinidamente, à reprodução do poder daqueles que historicamente dominaram o processo de produção do discurso verbal.

Uma última crítica ao modelo discursivo relaciona-se com a negligência de Habermas no que se refere às possibilidades (e à necessidade) de ampliação dos mecanismos institucionalizados de formação da vontade política, conferindo-se poderes efetivos aos deliberative publics. De fato, a preocupação de Habermas com a defesa do caráter institucional/constitucional do Estado de direito, assim como a influência da teoria parsoniana sobre o autor, a qual enfatiza a distinção e a necessidade de preservação de códigos de coordenação específicos nos diferentes sistemas (a sociedade civil produz influência política, mas não decide nem implementa políticas), levam-no a subestimar completamente as estruturas de participação pública. Dessa maneira, em toda a sua discussão sobre espaço público, faltam referências à necessidade de horizontalizar os processos decisórios (Schmalz-Bruns, 1994) ou à necessidade de promover processos de "alfabetização política", que permitam, no plano local, a vivência da noção de poder (Epple-Gass, 1992:120 e ss.).

Vários autores têm buscado preencher tal lacuna no modelo discursivo, insistindo na necessidade de conectar os processos de discussão e deliberação pública, de sorte a permitir que o debate político gere não apenas possibilidades de consenso, mas transparência no exercício do poder. Dessa forma, "um sistema político legítimo deve promover a deliberação, aumentando assim as possibilidades de decisões corretas (ou válidas, justas ou verdadeiras)" (Bohman 1996:6; ver, também, 
Avritzer, 2002:48 e ss.). Não se trata, naturalmente, de retomar os pressupostos teóricos dos democratas participativos dos anos 70 . Para aqueles, a participação era justificada ora com o argumento pluralista que indicava a necessidade de fomentar formas neocorporativistas de representação de interesses, ora com o argumento republicano que apontava os atores participativos como legítimos per se. No marco atual da democracia deliberativa, trata-se, diferentemente, de buscar estender a racionalidade comunicativa aos processos decisórios, assegurando-se, institucionalmente, a existência de fóruns deliberativos.

\section{Esfera pública mundial: breve digressão sobre um conceito equívoco}

O surgimento da esfera pública, em seu sentido moderno, é inseparável do processo de constituição dos Estados-nação e da formação das comunidades nacionais como um público integrado que, em geral, fala o mesmo idioma - há obviamente a exceção das nações multilíngües - e compartilha, em alguma medida, um cotidiano ou mundo da vida comum e uma cultura política construída coletivamente. À construção institucional do Estado-nação corresponde, portanto, no plano cultural, a formação das esferas públicas nacionais, no interior das quais são produzidos e reproduzidos os signos identitários que definem a nação. Tal processo de construção simbólica da nação se dá, conforme Bhabha (1994:139 e ss.), com base na tensão entre uma ação pedagógica e outra performativa. A ação pedagógica toma a comunidade nacional como objeto dos discursos que enfatizam a origem comum e os laços supostamente primordiais que unem os diferentes membros da nação. Por meio da ação performativa, os símbolos nacionais são atualizados e reinterpretados, fazendo com que os membros da nação se tornem assim sujeitos da reposição viva e permanente do que se acredita ser o destino comum da comunidade nacional. Essa dupla operação discursiva confere realidade à comunidade nacional imaginada, estabelecendo, ao mesmo tempo, seu ser e seu provir, a essência que a ela vincula um povo, uma cultura e um território, e o movimento, a transformação. Nesse contexto, a esfera pública constitui a arena viva e dinâmica na qual permanente processo de construção, desconstrução e reconstrução discursiva e simbólica da nação tem lugar. 
A formação das esferas públicas modernas dá-se historicamente, portanto, de forma concomitante com a constituição dos Estados nacionais e a definição da nação como uma comunidade política autônoma que define soberanamente seus destinos. É também no âmbito nacional que radicam as bases da cidadania moderna, concebida como o conjunto de direitos e deveres cabíveis àqueles que fazem parte da nação.

O papel democrático e democratizante assumido pela esfera pública no âmbito das fronteiras nacionais na política contemporânea tem levado alguns autores a postular que só mesmo a constituição de uma esfera pública mundial poderia construir as bases de uma ordem democrática no mundo globalizado (Fraser, 2002; Brunkhorst, 2002). No âmbito dos processos de formação dos blocos regionais, seja na Europa, seja nas Américas, a possibilidade de constituição de uma esfera pública transnacional como resposta democrática à integração econômica tem ocupado lugar igualmente importante nas discussões.

O próprio Habermas, ao discutir a unificação européia, aponta a necessidade de constituição de uma esfera pública continental, capaz de funcionar como plataforma de construção de uma identidade cultural européia. Se, historicamente, se observa que "a cada novo impulso modernizante abrem-se os mundos da vida compartilhados intersubjetivamente, para [depois] se reorganizarem e novamente se fecharem" (Habermas, 1998:126; ver, também, Habermas, 2001), faz-se necessário encontrar novas formas de acomodação social compatíveis com a vertiginosa ampliação de horizontes pessoais e sociais proporcionada pela globalização. Da mesma maneira que a identidade nacional se superpôs, ao longo da história, às lealdades religiosas ou locais, fornecendo uma plataforma para a integração social condizente com o contexto moderno, pós-tradicional e secularizado, faltam hoje novas possibilidades de reconstituição dos laços de integração e solidariedade social que, extrapolando as fronteiras nacionais, correspondam à dinâmica econômica transnacional existente.

Mesmo no âmbito europeu, a proposta de Habermas de constituição de uma esfera pública continental tem enfrentado críticas severas. Muitos autores têm mostrado que não há plausibilidade empírica na proposta: não há indícios palpáveis de que uma esfera pública européia se encontre em formação (Eder, 2000). Argumenta-se ainda que a diversidade das origens dos habitantes da Europa contemporânea impede o recurso à história comum como fonte de constituição de 
uma identidade cultural efetivamente abrangente e mesmo que se chegasse a constituir algo como uma identidade comum, esta implicaria o permanente estabelecimento das fronteiras simbólicas de uma european membership e os processos de exclusão daí decorrentes (ver Costa, 2002).

De acordo com Eder, verifica-se, nos últimos anos, no espaço geográfico europeu, a consolidação de diversos espaços comunicativos para além das fronteiras nacionais, os quais não se encontram apoiados em mundos da vida compartilhados e tampouco na pertença abstrata a um povo europeu. Segundo o autor, ainda que a classe trabalhadora e os produtores rurais permaneçam um fenômeno nacional, as classes médias européias teriam se transnacionalizado: já existe uma cultura transnacional de movimentos sociais, de empresários e de jovens que se comunicam através da música ou do aprendizado de idiomas na internet. Também o cotidiano dos turistas e da comunidade científica mostra o surgimento de espaços de sociabilidade e de comunicação pós-nacionais. Ainda segundo Eder, a visão da comunidade comunicativa como a de um povo que fala o mesmo idioma representa apenas um caso particular da teoria, mas não um "requisito sistemático". Isto é, o coletivo nacional dotado de uma identidade cultural, ainda que se apresente particularmente bem provido de capital social para a comunicação, representa apenas uma das múltiplas teias comunicativas que se podem formar. A comunicação transnacional assume formas diversas e se efetiva em contextos variados: "no lugar da língua nacional aparecem metaforizações polissêmicas do traço comum, novas metanarrativas processadas através de conceitos como 'citizenship', 'comunidade de valores' ou sociedade da informação [...]" (Eder, 2000:178).

Entre as diferentes formas de comunicação e sociabilidade transnacional, aquelas estabelecidas pelas articulações de movimentos sociais de diferentes origens geográficas parecem ser as mais visíveis publicamente $^{2}$. Verifica-se aqui, efetivamente, a circulação de temas e argumentos relacionados com a eqüidade de gênero, direitos humanos ou proteção ambiental, de forma simultânea, em contextos nacionais diversos. Contudo, não se trata da formação de uma esfera pública transnacional que coloca em contato os diferentes públicos nacionais. Tem-se, na verdade, fóruns transnacionais diversos, segmentados e desarticulados entre si. Com efeito, discutidas transnacionalmente por um grupo restrito de ativistas, é através das estruturas das esferas 
públicas nacionais que as questões tratadas nesses contextos comunicativos transnacionais ganham repercussão, apresentando em cada país uma lógica nacional própria. Ou seja, os desenvolvimentos observados até o momento apontam para o fato de que não há a consolidação de nada que lembre uma esfera pública mundial, nos moldes em que foram constituídas as esferas públicas nacionais. Quando, por ocasião, por exemplo, de uma conferência de cúpula, determinados temas entram simultaneamente nas agendas das esferas públicas nacionais, o que se verifica não é um intercâmbio comunicativo entre as populações das diferentes regiões; há, nesses casos, uma troca de informações e experiências entre um conjunto reduzido de ativistas políticos que se incumbem então de fazer com que os temas debatidos com ativistas de diversos países circulem nas respectivas esferas públicas nacionais. A forma como tais temas são tratados internamente em cada país segue uma dinâmica própria, definida por fatores nacionais, como o nível de articulação dos atores sociais responsáveis pela difusão do tema, o grau de integração internacional da mídia nacional ou o interesse do governo nacional em incorporar o tema em questão à sua agenda (cf. Costa, 2002).

\section{Usos na América Latina}

O uso mais importante e generalizado do conceito de espaço público na América Latina ocorre nas pesquisas sobre os meios de comunicação de massa. Predomina aqui a visão herdada da sociologia da sociedade de massas e da recepção tardia do conceito de indústria cultural, conforme foi elaborado pela primeira geração da Escola de Frankfurt. Assim, esboça-se a imagem de um público atomizado e disperso que, de produtores críticos de cultura, se transformaram, no âmbito do processo mesmo de constituição da sociedade de massas, em consumidores passivos dos produtos da indústria cultural.

Os autores que seguem tal orientação teórica mostram que todos os desenvolvimentos históricos supostamente necessários para a transição à modernidade, como a reforma religiosa, a ideologia liberal-universalista, as revoluções burguesas etc., teriam faltado na América Latina (ver, entre outros, Brunner, 1994; García Canclini, 1990). Logo, a modernidade dá-se, entre nós, tardiamente, caracterizando a constituição de um plasma cultural híbrido, no qual as reminiscências de formas culturais tradicionais vão sucumbindo, ao longo do vertiginoso processo de urbanização e de fragmentação de 
identidades preexistentes, diante dos valores do individualismo e do "desejo de ser moderno" dos públicos educados. Essas visões de mundo seriam amplificadas e difundidas pelos meios de comunicação às novas massas urbanas, constituindo-se, nesse movimento, uma cultura:
“[...] que não reflete a alma de um povo, mas os desejos, anseios e a sensibilidade e o trabalho de uma 'nova classe' - os produtores e me- diadores simbólicos - e o trabalho gerador de milhões de recepto- res-consumidores que processam, interpretam, se apropriam e vivem à sua maneira, individual e às vezes coletivamente, essa massa de sig- nos produzidos e transmitidos" (Brunner, 1994:181).

No que diz respeito propriamente à esfera pública política, pode-se postular, seguindo tal visão, que as sociedades latino-americanas diferentemente do contexto europeu, onde a fragmentação urbana e a emergência da sociedade de massas teriam produzido a obliteração da esfera pública burguesa preexistente - seriam caracterizadas pela inexistência histórica de tal espaço comunicativo. São os meios de comunicação de massa que ocupariam, desde os primórdios da constituição de uma sociedade urbana na América Latina, o lugar das mediações sociais, estabelecendo "uma nova diagramação de espaços e intercâmbios urbanos" (García Canclini, 1990:49).

Não se espera obviamente que, nesse espaço público assenhoreado pela mídia, argumentos racionais sejam esgrimidos, questões substantivas sejam levadas a debate e posições doutrinárias e ideológicas claras e diferenciadas venham à tona. Diante da lógica própria da mídia, com ênfase na televisão, em cuja linguagem não cabem verdades matizadas nem longos exercícios argumentativos, mas apenas enunciados bombásticos, a política veria se esvaírem seus conteúdos; os próprios "personagens políticos não buscam distinguir-se por sua experiência, ou sua capacidade de liderança, mas pela simpatia que seus publicistas são capazes de suscitar entre os grandes auditórios" (Delarbre, 1994:48) ${ }^{3}$.

As análises da relação entre espaço público e democratização/democracia na América Latina mostram igualmente um gap na consideração de aspectos importantes que marcam a política no subcontinente. Os problemas manifestam-se já na ampla recepção da teoria da modernização até o começo dos anos 80 e implicam a assunção de três premissas básicas de tal teoria, quais sejam: o postulado da endoge- 
nia, segundo o qual as sociedades nacionais constituem um universo fechado no qual se dá inequívoca e linearmente a transformação conduzida pelas elites modernas; a suposição de uma subordinação das transformações políticas e culturais às mudanças econômicas; e a representação antinômica entre tradição e modernidade (cf. Knöbl, 2001). Nesse sentido, a modernização representaria, em cada uma das sociedades nacionais na América Latina, o processo linear que levaria à transformação das estruturas sociais e econômicas de tradicionais a modernas, entendidas como modernas as formas existentes nas sociedades (ocidentais) de industrialização pioneira (para um caso exemplar, ver Germani, 1981). Tal interpretação do processo de modernização origina uma concepção evolucionista da política e do espaço público: trata-se, fundamentalmente, da expectativa de que a modernização construiria per se estruturas de discussão pública e negociação de conflitos que se aproximariam progressivamente do similar "ocidental" (Avritzer, 2002:58 e ss.).

A teoria da dependência corrige a teoria da modernização em um ponto fundamental, ao mostrar que, no lugar da modernização unilinear no interior de uma sociedade isolada, há que se considerar, internamente, a multiplicidade de forças pró e contra a modernização e, externamente, a inserção de cada sociedade no contexto das relações de dependência entre centro e periferia no plano mundial (Cardoso e Faletto, 1979). Em seu entendimento da dinâmica entre economia e política, por um lado, e da relação entre tradição e modernidade, por outro, a teoria da dependência repete os problemas da teoria da modernização. Com efeito, os teóricos da dependência depreendem os atores políticos exclusivamente da dinâmica econômica e acreditam que as transformações na América Latina se dariam em um movimento cíclico: em um primeiro momento, os autores acreditavam que a modernização e a conseqüente democratização seriam conduzidas pela ação exclusiva das elites progressistas que, em um segundo momento, tratariam de incluir no projeto da nação modernizada o conjunto da população.

Os teóricos da transição (e da consolidação) democrática aprofundam a ruptura com a teoria da modernização operada pela teoria da dependência, na medida em que mostram que as elites não são, por definição, portadoras de valores modernos e democráticos. Daí a ênfase que os autores colocam no papel democratizante das instituições que devem assegurar a prevalência das incertezas do jogo político, 
mesmo contra a vontade das elites antidemocráticas ( $\mathrm{O}^{\prime}$ Donnell et alii, 1986; Diamond et alii, 1989). Em contrapartida, o papel da esfera pública na construção da democracia não é adequadamente considerado por tais autores, o que leva, no nosso entendimento, a pelo menos dois erros analíticos recorrentes das teorias da transição.

O primeiro problema diz respeito ao papel dos novos atores sociais que emergem no contexto da democratização (movimentos sociais, associações de vizinhos, ONGs etc.). Ao mesmo tempo que os autores em questão reconhecem a importância política desses, traduzem seu papel político sob a lente elite/massas do elitismo democrático, o que leva os teóricos da transição a subsumir tais atores ao jogo político entre as elites. Isto é, a contribuição dos novos atores sociais para a democratização se resumiria a fortalecer a posição das elites democráticas no jogo da política institucional, única arena em que a construção da democracia efetivamente acontece ${ }^{4}$.

O segundo problema refere-se às relações entre política e cultura, entendida pelos teóricos da transição como uma causalidade simples, ou seja, as mudanças político-institucionais e a vitória, no jogo político competitivo, das elites democráticas produziriam de imediato o enraizamento de valores e práticas democráticas no seio societário. Mesmo quando constata, já nos anos 90, no âmbito de sua reflexão sobre a "democracia delegativa", que a institucionalização da democracia nas novas poliarquias latino-americanas não havia abolido as práticas "clientelistas" e/ ou "particularistas", O'Donnell (1994; 1996) remete tais problemas a vícios da elite (Avritzer, 2002:32 e ss.). Falta, no caso de ambos os déficits constatados, um conceito substantivo de espaço público que permita, no primeiro caso, entender como, nessa esfera, se constroem, pela comunicação pública, a legitimidade e o poder efetivo que conquistam os novos atores sociais e, no segundo caso, mostrar como a existência ou inexistência de uma esfera pública politicamente atuante tem papel fundamental na construção de uma cultura democrática e na constituição de mecanismos de fiscalização pública que inibissem o clientelismo e o particularismo.

\section{CONCLUSÕES: ESFERA PÚBLICA E AS NOVAS DEMOCRACIAS LATINO-AMERICANAS}

As transformações recentes por que vem passando a esfera pública na maior parte dos países latino-americanos no bojo daquilo que Dagni- 
no (2002b; ver, também, Alvarez et alii, 1999) chamou de convergência perversa, qual seja, a coincidência entre os ciclos de democratização e de reformas neoliberais, são múltiplas e ambivalentes. De um lado, observa-se que uma intensa pluralização societária acompanha a liberalização dos mercados e a consolidação da integração da América Latina no contexto mundial. Ao mesmo tempo, como conseqüência de décadas de crescimento urbano não-planejado e de cortes de investimento social impostos pelos programas de ajuste estrutural, assiste-se a uma fragmentação sem paralelo dos espaços públicos locais, que sucumbem diante do avanço da violência e da instrumentalização das relações sociais locais pelas redes do crime organizado.

Do ponto de vista político, os processos de reforma do Estado, que impõem cortes orçamentários em áreas vitais, coincidem com programas efetivos de inovação institucional, capazes de dar transparência ao processo político e de abrir esferas do Estado à participação e à deliberação públicas.

No campo dos meios de comunicação, os desenvolvimentos são igualmente ambivalentes. Por um lado, os processos recentes de concentração da propriedade e os mecanismos historicamente prevalecentes na distribuição de licenças de operação nos forçam a reconhecer que a mídia conforma um campo no qual formas tradicional-populistas de conquista de lealdade política se misturam a novas estratégias de conquista de apoio das massas. Mas, simultaneamente, os meios de comunicação apresentam um conjunto de mudanças positivas para a expansão da democracia. Não há dúvida que o campo da esfera pública controlado pelos meios de comunicação de massa mostra relativa porosidade para absorver e processar os temas colocados pelos atores da sociedade civil. Ademais, desenvolvimentos, como a difusão de um estilo de jornalismo investigativo e a própria preservação do espaço de afirmação da autonomia de quem produz o material divulgado pela mídia (jornalistas, produtores culturais etc.), fazem dos meios de comunicação ator importante na construção do espaço público. Tais mudanças não podem ser adequadamente identificadas por via de concepções baseadas na sociologia das sociedades de massa, hegemônicas na investigação da mídia na América Latina.

As teorias da transição, por sua vez, mostram-se igualmente desprovidas de instrumentos para identificar o potencial democrático tanto 
da pluralização societária referida, quanto dos novos canais de comunicação entre a sociedade civil, de um lado, e o Estado e o sistema político, de outro. Tais desenvolvimentos concorrem para a construção daquilo que, seguindo a tradição da teoria crítica descrita acima, chamamos de esfera pública. Malgrado a metáfora espacial que sugere, equivocadamente, a existência de uma localização específica na topografia social, a esfera pública diz respeito mais propriamente a um contexto de relações difuso no qual se concretizam e se condensam intercâmbios comunicativos gerados em diferentes campos da vida social. Tal contexto comunicativo constitui uma arena privilegiada para a observação da maneira como as transformações sociais se processam, o poder político se reconfigura e os novos atores sociais conquistam relevância na política contemporânea.

Sem querer abreviar, ao contrário, com o intuito de estimular um debate que apenas se inicia, gostaríamos de concluir insistindo que o uso de uma concepção discursiva de espaço público na América Latina implica levar adequadamente em conta as correções feitas a tal modelo, quais sejam:

- A incorporação dos new publics. Salta aos olhos o processo recente de diversificação cultural e societária na América Latina. Observa-se a emergência de uma multiplicidade de novos atores urbanos, novas subculturas, novas etnicidades que contrastam com a imagem das nações homogeneamente mestiças historicamente construídas. Socialmente, a heterogeneização, para o bem e para o mal, não é menor. Os modelos instituídos de famílias, os modelos tradicionais de relações de gênero, as opções "convencionais" de sexualidade etc. vêm sendo crescentemente confrontados com novas formas de vida e comportamento.

- A relevância dos subaltern counterpublics. Cabe destacar o papel daqueles atores sociais que representam grupos tradicionalmente excluídos do espaço público, mas que, ao mesmo tempo, denunciam os limites do espaço político estabelecido e reivindicam seu direito de participar nele. As Madres de la Plaza de Mayo na Argentina, o Movimento dos Trabalhadores Rurais Sem Terra no Brasil ou o Ejército Zapatista de Libertación Nacional no México são exemplos de tais contrapúblicos.

- A emergência de diasporic publics. Os novos atores diaspóricos não se formam apenas naquele sentido original descrito por Paul Gil- 
roy, referindo-se à diáspora africana. De fato, os atores que reclamam a herança africana e apresentam ao espaço público nacional sua estética desafiadora daquilo que se constituiu, historicamente, como representação nacional, ganham importância em várias regiões, em especial na Colômbia e no Brasil. Não obstante, a idéia de públicos diaspóricos contempla todos os novos públicos que apresentam uma inserção ambivalente no espaço público nacional: ao mesmo tempo que partilham dele, compartilham redes transnacionais e se constituem como agentes permanentes de introdução de inovações sociais no contexto nacional. Estes são os casos das redes transnacionais de movimentos sociais e dos imigrantes transnacionais. Recorde-se que não se trata aqui da formação de um espaço público transnacional, mas de contextos comunicativos transnacionais múltiplos não necessariamente interligados.

- A multiplicação dos deliberative ou participatory publics. O modelo discursivo de espaço público enfatiza a necessidade de separação clara de funções entre a sociedade civil e a sociedade política e de autolimitação dos atores civis. As reservas são compreensíveis se se considera que o modelo foi formulado por referência empírica a um contexto em que há mecanismos efetivos de controle do Estado pelos cidadãos e os partidos políticos, a despeito do desencantamento dos últimos tempos, ainda funcionam como estruturas eficientes de intermediação entre a sociedade civil e o sistema político. Na América Latina, contudo, os partidos se constituíram, historicamente, a partir de máquinas partidárias capazes de distribuir, privadamente e por meio de acordos clientelistas, benefícios públicos. Nesse sentido, cabe uma ênfase distinta nas articulações entre os processos de deliberação pública e tomada de decisão na América Latina. É preciso que, no seio de uma esfera pública porosa e pulsante, temas, posições e argumentos trazidos pelos novos atores sociais encontrem formas institucionais de penetrar o Estado e, por essa via, democratizá-lo, tornando-o objeto de controle dos cidadãos.

(Recebido para publicação em outubro de 2004)

(Versão definitiva em dezembro de 2004) 


\section{NOTAS}

1. O livro Mudança Estrutural da Esfera Pública publicado, originalmente, por Habermas em 1962 foi traduzido dez anos mais tarde para o francês e o italiano e somente nos anos 80 para o português, espanhol e o inglês (ver Sabato, 2000).

2. Estudando as redes de atores sociais no contexto latino-americano, Scherer-Warren (2001) observou que várias delas se tornaram fóruns regulares de troca sistemática de experiências de agentes provindos de diferentes regiões do continente, diferenciando-se e constituindo suas identidades por meio dos temas que tratam, destacando-se aqui: i) redes filantrópicas, dedicadas à solidariedade material; ii) redes humanitárias, especializadas na defesa dos direitos humanos e de minorias; iii) redes identitárias, integradas a partir da defesa comum de identidades de gênero, étnicas etc.; iv) redes de ações educativas, articuladas a partir de projetos educacionais com premissas comuns desenvolvidos em partes distintas do continente; $v$ ) redes de defesa transnacional da cidadania, que se articulam, sobretudo, em torno das ações de oposição aos processos de integração econômica no continente.

3. Mesmo as abordagens mais diferenciadas constatam uma tendência inequívoca e unilateral de obliteração das possibilidades de comunicação pública. O teórico brasileiro mais importante da área da comunicação social, Moniz Sodré (1996), reconhece, é verdade, limites ao poder dos meios de comunicação de massa, mostrando que "as singulares estratégias de negociação simbólica que mantêm com seus públicos não deixam que se tornem mecânicas caixas de ressonância das empresas e do Estado". Não obstante, não abandona as premissas das teorias que descrevem o espaço público unilateralmente como encenação política, quando afirma que "seja pela criação de uma realidade social despolitizada, seja pela estimulação de técnicas plebiscitárias de sondagem de opinião pública ou então pela simples conversão das campanhas eleitorais em táticas mercadológicas", minam-se as bases constitutivas da esfera pública e da política representativa.

4. Uma outra maneira equivocada de tratar os novos atores é aquela legada por uma compreensão da democracia como um mercado político. Ela se manifesta, por exemplo, na crítica de Reis (1994) às concepções comunicativas de poder e democracia. Para o autor, o espaço público constitui a arena de disputa e afirmação de interesses sociais particulares, sem que haja, neste jogo, qualquer ator social altruísta ou capaz de representar questões relevantes para o conjunto da sociedade: "Se se considera o caráter estratégico dos movimentos [sociais] e sua busca de afirmação de objetivos próprios contra as disposições de outros atores, é bastante claro que eles compartilham em alguma medida com os grupos de interesse o caráter de particularismo tendencialmente aético [...]" (idem:340). Para Reis, portanto, o espaço público é parte constitutiva de um mercado político, no qual os diferentes grupos de interesse disputam as atenções públicas, impondo-se não pela força mobilizadora dos argumentos que trazem à luz, mas pelo poder de controlar as estruturas comunicativas públicas. 


\section{REFERÊNCIAS BIBLIOGRÁFICAS}

ADORNO, T. e HORKHEIMER, M. (1964), The Dialectic of Enlightenment. New York, Herder \& Herder.

ALVAREZ, S., DAGNINO, E. e ESCOBAR, A. (eds.). (1999), Cultures of Politics, Politics of Cultures. Boulder, Co., Westview Press.

ARENDT, H. (1959), The Human Condition. Chicago, Chicago University Press.

AVRITZER, Leonardo. (1996), A Moralidade da Democracia. São Paulo/Belo Horizonte, Perspectiva/Editora da UFMG.

. (1999), “Diálogo y Reflexividad: Acerca de la Relación entre Esfera Pública e Medios de Comunicación". Metapolítica, vol. 3, no 9, México.

. (2002), Democracy and the Public Space in Latin America. Princeton/Oxford, Princeton University Press.

BENHABIB, S. (1995), Democracy and Difference: Contesting the Boundaries of the Political. Cambridge, Ma., MIT Press.

BHABHA, H. (1994), The Location of Culture. London/New York, Routledge.

BOHMAN, J. (1996), Public Deliberation: Pluralism, Complexity and Democracy. Cambridge, Ma., MIT Press.

BRUNKHORST, H. (2002), Solidarität. Von der Bürgerfreundschaft zur globalen Rechtsgenossenschaft. Frankfurt/M., Suhrkamp.

BRUNNER, J. J. (1994), Cartografias de la Modernidad. Santiago, Dolmen Ediciones.

CALHOUN, C. (org.). (1992), Habermas and the Public Sphere. Cambridge, Ma., MIT Press.

CARDOSO, F. H. e FALETTO, E. (1979), Dependency and Development in Latin America. Berkeley, University of California Press.

COHEN, J. (1985), "Strategy or Identity: New Theoretical Paradigms and Contemporary Social Movements". Social Research, vol. 52, no 4, pp. 663-716.

e ARATO, A. (1992), Civil Society and Political Theory. Cambridge, Ma./London, MIT Press.

COSTA, S. (1994), “Esfera Pública, Redescoberta da Sociedade Civil e Movimentos Sociais no Brasil. Uma Abordagem Tentativa". Novos Estudos CEBRAP, nํ38, pp. 38-52. . (1997), Dimensionen der Demokratisierung. Frankfurt/M., Vervuert. . (1999), “La Esfera Pública y las Mediaciones entre la Cultura y la Política: El Caso de Brasil". Metapolítica, vol. 3, nº 9, México.

_. (2002), As Cores de Ercília. Belo Horizonte, Editora da UFMG.

DAGNINO, Evelina (org.). (2002a), Sociedad Civil, Esfera Pública y Democratización en América Latina: Brasil. México/Campinas, SP, Fondo de Cultura Económica/Unicamp.

__ (org.). (2002b), Sociedade Civil e Espaços Públicos no Brasil. São Paulo, Paz e Terra. 


\section{Leonardo Avritzer e Sérgio Costa}

DEETZ, S. (1992), Democracy in the Age of Corporate Colonization. New York, Sunny University Press.

DELARBRE, Raul T. (1994), “¿Videopolítica vs. Mediocracia? Los Medios y la Cultura Democrática". Revista Mexicana de Sociología, 3/94.

DIAMOND, L. J., LINZ, J. e LIPSET, S. (1989), Democracy in Developing Countries. Boulder, Co., Lynn e Rienner.

DOWNS, A. (1956), An Economic Theory of Democracy. New York, Harper.

DRYZEK, J. (1990), Discursive Democracy. Cambridge, Cambridge University Press.

EDER, K. (2000), "Zur Transformation nationalstaatlicher Öffentlichkeit in Europa". Berliner Journal für Soziologie, $\mathrm{n}^{\mathrm{o}} 2$, pp. 167-184.

EPPLE-GASS, R. (1992), “Volkssouveranität statt Systemlegitmierung”. Widerspruch, 24.

FRASER, N. (1992), "Rethinking the Public Sphere: A Contribution to the Critique of Actually Existing Democracy", in C. Calhoun (org.), Habermas and the Public Sphere. Cambridge, Ma., MIT Press.

. (2002), Transnationalizing the Public Sphere. New York. Manuscrito.

GARCÍA CANCLINI, N. (1990), Culturas Híbridas. México, Grijalbo.

GERMANI, Gino. (1981), The Sociology of Modernization. New Brunswick, Transaction Books.

GILROY, Paul. (1993), The Black Atlantic: Modernity and Double Consciouness. Cambridge, Ma., Harvard University Press.

GOLDFARB, J. (1989), After the Fall. New York, Basic Books.

GUTMAN, A. (1994), Multiculturalism. Princeton, Princeton University Press.

HABERMAS, J. (1981), Theorie des kommunikativen Handelns (vol. 2). Frankfurt/M., Suhrkamp.

. (1985), Der philosophische Diskurs der Moderne. Frankfurt/M., Suhrkamp.

. (1990), “Neues Vorwort”. Strukturwandel der Öffentlichkeit. Frankfurt a. M., Suhrkamp.

. (1992a), Faktzität und Geltung. Beiträge zur Diskurstheorie des Rechts und des demokratischen Rechtsstaats. Frankfurt/M., Suhrkamp.

. (1992b), “Drei normative Modelle der Demokratie: Zum Begriff deliberativer Politik", in H. Münkler (org.), Die Chancen der Freiheit - Grundprobleme der Demokratie. München, Piper.

__. (1998), Die postnationale Konstellation. Politische Essays. Frankfurt/M., Suhrkamp.

__. (2001), Zeit der Übergänge. Frankfurt/M., Suhrkamp.

HELD, D. (1987), Models of Democracy. Stanford, Stanford University Press.

JAY, M. (1973), The Dialectical Imagination. Boston, Little Brown.

KEANE, J. (1988), Civil Society and the State. London, Verso. 
Teoria Crítica, Democracia e Esfera Pública: Concepções e Usos...

KNÖBL, W. (2001), Spielräume der Modernisierung. Das Ende der Eindeutigkeit. Weilerwist, Velbrück.

MELUCCI, A. (1985), “The Symbolic Challenge of Contemporary Movements". Social Research, vol. 52, no 4 .

. (1989), Nomads of Present. Philadelphia, Temple University Press.

. (1996), Challenging Codes. Cambridge, Cambridge University Press.

O’DONNELL, G. (1994), “Delegative Democracy”. Journal of Democracy, vol. 5, nº 1, pp. 55-69.

. (1996), "Illusions about Consolidation". Journal of Democracy, vol. 7, no 2, pp. 34-51.

_ SCHMITTER, P. e WHITEHEAD, L. (eds.). (1986), Transitions from Authoritarian Rule. Baltimore/London, The Johns Hopkins University Press.

OLVERA, Alberto J. (1999), “Los Modos de Recuperación Contemporánea de la Idea de Sociedad Civil", in A.J. Olvera (org.), La Sociedad Civil. De la Teoría a la Realidad. México, El Colegio de México, pp. 27-53.

__ (org.). (2003), Sociedad Civil, Esfera Pública y Democratización en América Latina: México. México, Xalapa/Fondo de Cultura Económica/Universidad Veracruzana.

PANFICHI, Aldo (org.). (2002), Sociedad Civil, Esfera Pública y Democratización en América Latina: Andes y Cono Sur. México, Fondo de Cultura Económica.

PATEMAN, C. (1970), Participation and Democratic Theory. Cambridge, Cambridge University Press.

REIS, F. W. (1994), “Cidadania, Mercado e Sociedade Civil”, in E. Diniz et alii (orgs.), O Brasil no Rastro da Crise. São Paulo, AnPOCs/Hucitec, pp. 328-349.

SABATO, H. (2000), "Öffentlichkeit in Iberoamerika. Überlegung zum Gebrauch einer Kategorie”, in P. Hengstenberg, K. Kohut e G. Maihold (orgs.), Zivilgesellschaft in Lateinamerika. Interessenvertretung und Regierbarkeit. Frankfurt/M., Vervuert, pp. 53-66.

SARTORI, G. (1987), The Theory of Democracy Revisited. New Jersey, Chatham Publishers.

SCHERER-WARREN, I. (2001), Redes e Movimentos Sociais. Seminário Estudos e Pesquisas sobre ONGs na América Latina, Florianópolis. Manuscrito.

SCHMALZ-BRUNS, R. (1994), "Zivile Gesellschaft und reflexive Demokratie". Forschungsjournal NSB, 1/94, pp. 18-34.

SCHUMPETER, J. (1944), Capitalism, Socialism and Democracy. New York, Harper.

SODRÉ, M. (1996), Reinventando a Cultura: A Comunicação e seus Produtos. Petrópolis, RJ, Vozes.

THOMPSON, J. (1990), Ideology and Modern Culture. Cambridge, Polity Press. . (1995), Media and Modernity. Cambridge, Polity Press. 


\begin{abstract}
Critical Theory, Democracy, and the Public Sphere: Concepts and Uses in Latin America

In this article we analyze the construction of the concept of public sphere within critical theory, discussing its recent reformulations and reinterpretations. Our primary aim is to focus on contributions that emphasize the increasing importance of new publics, subaltern counter-publics, diasporic publics, and deliberative publics in contemporary democracies. We seek to outline a broader concept of public sphere in order to offer an adequate instrument for analyzing the simultaneous cycles of democratization and structural adjustment in Latin America.
\end{abstract}

Key words: critical theory; public sphere; Latin America

\title{
RÉSUMÉ
}

Théorie critique, démocratie et sphère publique: conceptions et usages en Amérique Latine

Dans cet article, on passe en revue la construction de l'idée de sphère publique dans le cadre de la théorie critique, ainsi que des corrections à ce concept effectuées récemment. On y étudie particulièrement des éléments complémentaires avec pour conséquence le besoin de prendre en compte adéquatement les new publics, subaltern counterpublics, diasporic publics et deliberative publics. On s'efforce de proposer une conception élargie de sphère publique, de façon à constituer un instrument approprié à l'étude des cycles simultanés de démocratisation et d'accord structurel en Amérique Latine.

Mots-clé: sphère publique; théorie critique; Amérique Latine 